\title{
ESTATUTO CIENTÍFICO E RELAÇÕES DE PODER: CLAUDE RAFFESTIN E O PROJETO EPISTÊMICO NA GEOGRAFIA POLÍTICA
}

\author{
Raquel Fulino de Souza ${ }^{1}$
}

\begin{abstract}
Resumo: Embora seja inegável a larga difusão das ideias de Claude Raffestin no Brasil, principalmente àquelas que dizem respeito às relações de poder, à produção de territórios e à territorialidade humana, consideramos ainda desconhecidos determinados aspectos teóricos de suas reflexões nos debates da geografia nacional. O objetivo deste artigo consiste, portanto, em identificar os aspectos categoriais e metodológicos da reflexão do geógrafo suíço, os quais tornaram possível sua "geografia do poder" e a consolidação das bases científicas (estatuto científico) de sua abordagem relacional. Neste sentido, o artigo cumpre sua tarefa em particularizar as questões epistêmicas, metodológicas e, inclusive, ideológicas do pensamento de Raffestin, estimulando, de um lado, as interlocuções teóricas mais ampliadas no tocante às suas contribuições na geografia humana, e, de outro, reavivar novas reflexões no campo da geografia política e do pensamento geográfico.
\end{abstract}

Palavras-chave: Claude Raffestin; Cientificidade; Poder; Relações Sociais; Território.

\section{SCIENTIFIC STATUTE AND POWER RELATIONSHIPS: CLAUDE RAFFESTIN AND THE EPISTEMIC PROJET IN POLITICAL GEOGRAPHY}

\begin{abstract}
Although the wide dissemination of Claude Raffestin's ideas in Brazil, especially those concerning power relations, the production of territories and human territoriality is undeniable, we also consider certain theoretical aspects of his reflections in the debates of the national geography as yet unknown. The objective of this article is to identify the categorical and methodological aspects of the Swiss geographer's reflection, which made possible his "geography of power" and the consolidation of the scientific bases of his relational approach. In this sense, the article fulfills its task of particularising the epistemic, methodological and even ideological questions of Raffestin's thinking, stimulating, on the one hand, the broader theoretical dialogues regarding their contributions in human geography, and, on the other hand, revive new reflections in the field of political geography and geographic thought.
\end{abstract}

Keywords: Claude Raffestin; Scientificity; Power; Social Relationships; territory.

\footnotetext{
${ }^{1}$ Doutoranda em Geografia pela Universidade Estadual Paulista (UNESP) - Campus de Rio Claro (Doutorado Direto). sirfulino@yahoo.com.br

Estudos Geográficos, Rio Claro, 17(1): 309-322, jan./jun. $2019 \quad$ (ISSN 1678-698X) http://www.periodicos.rc.biblioteca.unesp.br/index.php/estgeo
} 


\section{INTRODUÇÃO}

Uma situação absolutamente corrente nas produções geográficas contemporâneas tem mostrado uma série de reproduções irrefletidas de determinadas expressões particulares e "chavões teóricos" de certas referências autorais na composição de artigos e trabalhos acadêmicos. Desencadeadas pela pressão institucional e de financiamentos em torno das publicações, ou, então, pela própria indolência reflexiva que tem assaltado os ânimos dos geógrafos, essas reproduções são marcadas, de um lado, pela negação da reflexão, e por outro, pelas apropriações descontextualizadas e reducionistas de seus autores.

Constatamos que não raro o pensamento de Claude Raffestin tem tomado tais caminhos, pois, embora seja patente que alguns aspectos de seu projeto teórico mereçam, de fato, grandes destaques, suas contribuições filosóficas e científicas ao longo de quarenta anos de trajetória intelectual foram reduzidas, muitas vezes, às questões do poder foucaultiano e das relações que produzem os territórios.

Com base nestes argumentos, nosso objetivo consiste em capturar alguns "momentos cristalizados" da reflexão do geógrafo suíço, os quais balizaram a construção de sua "geografia do poder", sobretudo no que diz respeito ao estatuto epistêmico de sua abordagem relacional. Para isto, esta tarefa envolve a necessidade de circunscrever os momentos epistêmicos, metodológicos e também ideológicos do autor, sinalizando, inclusive, suas questionáveis demarcações no que diz respeito à cientificidade geográfica.

Os tensionamentos críticos, neste sentido, oportunizam breves reflexões de método, de modo que começaremos nesta discussão. Em seguida, refletiremos, especificamente, sobre o projeto epistemológico de Claude Raffestin no âmago da geografia política dos anos de 1980, manifestando as posições do autor em relação aos processos de conceitualização da geografia humana, suas divergências para com a geografia física e suas críticas ao essencialismo científico (ou a busca pelo objeto de estudo).

\section{A NATUREZA ONTOLÓGICA DAS CATEGORIAS E A BASE MATERIAL DAS RELAÇÕES DE PODER}

Um dos principais aspectos que permite adentrar uma discussão de método é, sem dúvida, a questão da especificidade das categorias e conceitos na ordenação do discurso metódico.

Isto quer dizer que os traços metódicos constitutivos das categoriais e conceitos revelam as preocupações centrais de seus autores, que abrangem, se for possível sermos sucintos, as mediações entre os fenômenos da realidade objetiva e os produtos mentais (teorias, modelos, conceitos, entre outros) operados e desenvolvidos pelos pesquisadores. A partir destas mediações, a colocação em evidência do autor em relação aos aspectos gnosiológicos e ideológicos de seu discurso tornam-se mais demarcados.

Neste sentido, a natureza e a especificidade das categorias das leis estruturantes do real na ordem do desenvolvimento do conhecimento humano permitem situar as correlações fundamentais entre "o particular e o geral na realidade objetiva e na consciência, assim como a colocação em evidência da

Estudos Geográficos, Rio Claro, 17(1): 309-322, jan./jun. 2019 (ISSN 1678-698X) http://www.periodicos.rc.biblioteca.unesp.br/index.php/estgeo 
origem das essências ideais e da relação destas últimas com as formações materiais" (CHEPTULIN, 1982, p. 05).

As mediações fundamentais do discurso metódico sinalizam duas amplas trajetórias de reflexão acerca dos processos de conceitualização de uma ciência particular.

De um lado, verificamos as abordagens predominantemente lógicoepistêmicas, que exprimem "preceitos meramente gnosiológicos como critérios fundamentais de constituição das matrizes categoriais" (SANTOS NETO, 2011, p. 37). Trata-se de um discurso científico que pretende expressar apenas logicamente sua estrutura de conceitos, erigindo uma verdadeira arquitetura categoriais que constrói a realidade mediante leis a priori, eliminando, muitas vezes, a complexidade de relações históricas e determinações concretas de uma dada processualidade em questão.

Esta circunscrição crítica mostra que os processos de conceitualização de um projeto epistêmico, em concordância com Souza (2009; 2008), não são meros apanágios conceituais ou constructos taxonômicos de uma ciência particular. Esses produtos do pensar são, antes de tudo, fenômenos ontogenéticos concretos que se manifestam e se consolidam mediante determinações da praxis humana (SOUZA, J. G., 2013).

Isto significa, novamente explicando, que as funções representativas oriundas das categorias lógico-epistêmicas em relação à possibilidade do conhecimento humano sobre o real são amparadas por leis a priori, que se sobrepõem às relações sociais e à materialidade do mundo objetivo, projetando concepções que pretendem transcender e atravessar quaisquer condições sóciohistóricas precisas.

Este último apontamento inaugura as bases para a segunda abordagem no tocante à natureza das categorias e na produção do conhecimento da realidade, apontando que "as categorias [...] exprimem formas de vida, determinações de existência" (MARX, 2008, p. 265) da totalidade concreta, conferindo, por sua vez, seu caráter absolutamente terreno.

Assim, a apreensão do ordenamento ou da articulação categorial não indica, porém, um processo a priori e independente de ordenamento categorial no plano teórico ou, como melhor explica Müller (1982, n/p), "as categorias não são abstrações teóricas do analista, elas são expressões teóricas da abstração real”, tendo em vista seu caráter histórico-imanente, ou seja, ontológico.

Compete relembrar, assim, que, nesta perspectiva materialista e ontológica, inexiste a pretensão metódica de encontrar o caminho da unidade lógica e resolutiva entre sujeito e objeto, ou a articulação entre a ordem do ser e a ordem do pensamento (SANTOS NETO, 2011). Não se busca, portanto, a "verdade" epistemológica, a objetividade enquanto tal, em-si (CHASIN, 2009), sinalizando, na verdade, seu propósito para uma construção metodológica cientificamente capaz de "desmistificar contradições reais" (MÜLLER, 1982).

Portanto, "a problemática do conhecimento é, marxianamente, uma questão de caráter e resolução ontognosiológica" (VAISMAN, ALVES, 2009, p. 10), ou seja, "a questão do saber em Marx está categorialmente subordinada à dilucidação ôntica, ao exercício da escavação pelo ser das coisas" (VAISMAN, ALVES, 2009, p. 12), cuja "determinação última é uma contradição real e não a automanifestação da razão" (MÜLLER, 1982).

Por conseguinte, como veremos, estas breves considerações metodológicas permitem tensionar, do ponto de vista material e ontológico, o que Claude Raffestin

Estudos Geográficos, Rio Claro, 17(1): 309-322, jan./jun. 2019 (ISSN 1678-698X) http://www.periodicos.rc.biblioteca.unesp.br/index.php/estgeo 
identificou no âmago de sua geografia política, justamente por não enfatizar uma dimensão estática e monolítica, como o espaço vidalina ou o Estado (da geografia política clássica), mas as relações de poder que fundam os territórios.

Acompanhando as expressões de Raffestin, os processos relacionais efetivados no espaço, isto é, o exercício do poder objetivado nessa "realidade material preexistente a qualquer conhecimento e a qualquer prática" (RAFFESTIN, 1993, p. 144), são capazes de revelar (representar) as projeções de "um trabalho, seja energia e informação" (RAFFESTIN, 1993, p. 144), engendrando, por sua vez, as condições necessárias e instauradoras dos territórios.

Neste sentido:

L'espace est un enjeu du pouvoir tandis que le territoire est un produit du pouvoir dans le sens où le pouvoir n'est pas la «nécessité naturelle, mais la capacité qu'ont les hommes de transformer par leur travail à la fois la nature qui les entoure et leurs propres rapports sociaux ${ }^{2}$ (RAFFESTIN, 1982, p. 168, destacado pela autora).

Trata-se de um questionamento que revela sua importância, inclusive, pela própria centralidade que a semiologia e a linguística adquirem na estrutura de pensamento de Raffestin, a ponto de se considerar que "os sistemas sêmicos [...] realizam as objetivações do espaço, que são os processos sociais" (RAFFESTIN, 1993, p. 144).

Em outras palavras, cumpre demarcar, na trajetória de sua "geografia do poder", se os caminhos teóricos do autor assumiram um desenvolvimento predominantemente lógico-discursivo (gnosio-epistêmico ou apriorístico); ou, ao contrário, se o autor fornece elementos teóricos concretos de desmistificação das relações sociais de poder e do movimento contraditório dessa sociabilidade.

Cumpre reiterar, nesta direção, que este exercício reflexivo não denota qualquer tipo de "enquadramento" teórico-analítico, mas um reconhecimento de que os caminhos metodológicos e as concepções adotadas pelos pesquisadores não demonstram simples "preferências intelectuais". Em última instância, as opções metodológicas manifestam nuances e tentativas de oposição (dicotomização) ou articulação (aproximação) entre atividade científica e os aspectos ideológicos (LÖWY, 2000).

As práticas científicas, portanto, implicam determinações diretas ou indiretas, decisivas ou episódicas, no âmago da explicitação ou da atenuação (mistificação) científica dos conflitos e das injustiças sociais intrínsecos ao movimento real e contraditório da sociabilidade capitalista.

\footnotetext{
2 “O espaço é uma aposta do poder enquanto o território é um produto do poder no sentido onde o poder não é "a necessidade natural, mas a capacidade que tem os homens de transformar pelo seu trabalho, simultaneamente, a natureza que os rodeiam e suas próprias relações sociais" (Tradução livre).

Estudos Geográficos, Rio Claro, 17(1): 309-322, jan./jun. 2019 (ISSN 1678-698X) http://www.periodicos.rc.biblioteca.unesp.br/index.php/estgeo
} 


\title{
ESTATUTO CIENTÍFICO E CATEGORIAS GEOGRÁFICAS: REVISITANDO “POR UMA GEOGRAFIA DO PODER"
}

\begin{abstract}
Au moment d'écrire le premier mot relatif au sujet qu'énonce le titre, jé découvre mon "enfermement" dans des limites et des frontières mentales car "penser" implique, ipso facto, un système de limites ${ }^{3}$. (Claude Raffestin)
\end{abstract}

Ao reiterar alguns aspectos relativos às mediações existentes entre subjetividade e objetividade e a produção do discurso científico, debruçaremos, neste momento, sobre os contornos mais específicos de um projeto epistêmico de geografia humana dos anos de 1980.

Trata-se de um "programa de reflexão" desenvolvido pelo geógrafo suíço, Claude Raffestin, acerca das questões teóricas que envolvem as relações de poder e a conformação territorial. A análise de determinados pontos deste programa reflexivo engendra, na verdade, uma análise pormenorizada no que diz respeito ao próprio estatuto de cientificidade tomado pelo autor da disciplina geográfica. Isto, por sua vez, "s'exprime à travers une réflexion historique sur la nature des concepts utilisés, [et] révèle une inquietude qui déclenche un examen épistémologique de la géographie humaine ${ }^{4}$ (RAFFESTIN, 1974, p. 22).

Se prestarmos atenção nas reflexões iniciais contidas em "Por Uma Geografia do Poder" (1993 [1980]), Raffestin apresenta o caráter desafiador de suas preocupações teóricas, questionando, inicialmente, a "perversidade classificatória" imputada aos geógrafos das diversas gerações em ter que ratificar, ao longo dos anos, as categorias de sua ciência.

Para desagrado do geógrafo suíço que sempre contestou a tradição vidalina, o procedimento comumente adotado pela tradição francesa consistia em operar as categorias a partir de um quadro apriorístico, cujas expressões teóricas fossem, inexoravelmente, "objeto de uma tradução espacial imediata" (RAFFESTIN, 1993, p. 05).

É evidente que, sob esses critérios, a noção de "poder" não foi, imediatamente, compreendida enquanto categoria geográfica, sendo mais acolhida entre os estudiosos das ciências políticas, da filosofia política e até mesmo da história.

Em todo caso, se, para Raffestin (1993), esta questão "depende da concepção epistemológica que fazemos das ciências do homem e, em consequência, da geografia humana" (p. 06), é preciso reiterar ainda que este aspecto também depende de uma concepção de método e, igualmente, de uma posição ideológica.

Em um artigo ${ }^{5}$ publicado dois anos antes de "Por Uma Geografia do Poder", o autor já manifestava alguns aspectos que rondam a natureza científica e nãocientífica do conhecimento humano, incitando processos de conceitualização que se distinguem de "simples" constructos ou noções sobre o real (RAFFESTIN, 1978).

\footnotetext{
3 "No momento de escrever a primeira palavra relativa ao tema que enuncia o título, eu descubro meu "fechamento" nos limites e nas fronteiras mentais, pois pensar implica, ipsu facto, um sistema de limites" (Tradução livre).

4 "se exprime através de uma reflexão histórica sobre a natureza dos conceitos utilizados, [e] revela uma inquietação que provoca um exame epistemológico da geografia humana" (Tradução livre).

${ }^{5}$ RAFFESTIN, C. "Les construits en géographie humaine: notions et concepts".

Estudos Geográficos, Rio Claro, 17(1): 309-322, jan./jun. 2019 (ISSN 1678-698X) http://www.periodicos.rc.biblioteca.unesp.br/index.php/estgeo
} 
Sabemos, neste sentido, que a palavra 'notion' provient d'une racine indoeuropéenne qui signifie 'connaître' c'est-à-dire appréhender par la perception"6 (RAFFESTIN, 1978, p. 60), de modo que "la notion permet d'organiser l'expérience, elle est un matériel empirique" (RAFFESTIN, 1978, p. 60). Em outras palavras, tratam-se de representações que conformam estruturas de sentidos e referenciais para o sujeito em relação ao real, porém não auferem inclinações explicativas e interpretativas dessa mesma realidade.

Já os processos de conceitualização, ao contrário, estão, constantemente, implicados no exercício da abstração teórica, tornando-os capazes d'"en reternir les aspects saillants" ${ }^{\prime}$ ou "les traits essentiels"9 (RAFFESTIN, 1978, p. 57) da realidade humana. Nesta perspectiva, os conceitos são, inegavelmente, constructos do pensamento, mas, ao mesmo tempo, se diferem das noções: "il ne s'agit plus de jouer sur le nombre des indices qui caractérisent un fait mais il s'agit de générer des relations formelles ou mathématiques indépendantes des contenus particuliers ${ }^{10 "}$ (RAFFESTIN, 1978, p. 61).

Neste ponto, em especial, Raffestin sustenta sua visão epistêmica acerca das funções precisas que os conceitos deveriam instaurar no interior das estruturas representativas e interpretativas de dada uma ciência, no caso, da "geografia humana".

Isto equivale dizer que a possibilidade de estabelecer relações formais entre os constructos (representações) deve-se, em grande medida, a outros elementos que derivam dos processos de conceitualização, tais como as fórmulas, os modelos ou mesmo a própria teoria ("megaconceitos") (RAFFESTIN, 1978). São, na verdade, instrumentos teóricos que incitam os geógrafos a pensar matematicamente e a apreender os fenômenos humanos mais complexos, gerando comparações e aquiescendo a conformação de "leis gerais" (nomotéticas) em suas propostas interpretativas (RAFFESTIN, 1978).

A busca por modelos matemáticos e pelo compromisso em estabelecer "leis" na ciência geográfica revela, na verdade, as tentativas teóricas do autor em decrescer as análises indutivas de seu tempo ${ }^{11}$, sobrelevando, no limite, uma abordagem hipotético-dedutiva.

De acordo com Raffestin; Lévy (1998), na pesquisa geográfica, o geógrafo é sempre confrontado com quatro elementos epistemológicos - a metafísica, a problemática, a teoria e a empiria -, de modo que o exame de "ces éléments dans l'ordre de la séquence proposée c'est se situer dans une perspective analytique de type hypothético-déductif qui est parmi les plus solidement fondés ${ }^{12}[\ldots]$ (RAFFESTIN; LÉVY, 1998, p. 33).

\footnotetext{
6 “'”noção' provém de uma raiz indo-europeia que significa ‘conhecer', ou seja, apreender pela percepção” (Tradução livre).

7 "a noção permite organizar a experiência, é um material empírico" (Tradução livre).

8 "reter os aspectos notáveis" (Tradução livre).

9 "os traços essenciais" (Tradução livre).

10 "não se trata mais de atuar sobre o número dos índices que caracterizam um fato, mas trata-se de gerar relações formais ou matemáticas independentes dos conteúdos particulares" (Tradução livre).

11 "Pour y parvenir, selon Piaget, il faut passer de l'idiographie au nomothétique, c'est-à-dire établir des lois autrement dit se situer dans éxperimentale et logico-mathématique" (RAFFESTIN, 1978, p. 63). "Para alcançar isto, segundo Piaget, é necessário passar da idiografia à nomotética, ou seja, estabelecer leis, dito de outra forma, se situar no experimental e lógicomatemático" (Tradução livre).

12 "destes elementos na ordem da sequência proposta, é se situar em uma perspectiva analítica do tipo hipotético-dedutivo que é, entre várias, uma das mais solidamente fundadas".

Estudos Geográficos, Rio Claro, 17(1): 309-322, jan./jun. 2019 (ISSN 1678-698X) http://www.periodicos.rc.biblioteca.unesp.br/index.php/estgeo
} 
Assim:

La métaphysique est, avant tout, un terme conventionnel qui désigne une très vaste région de la connaissance: de la connaissance innée ou "subjective» à la foi religieuse, des modalités affectives et éthiques qui orientent le comportement et forment les attitudes aux idéologies politiques et aux croyances superstitieuses. En quelque sorte, la métaphysique joue le rôle de réservoir d'impressions, de convictions et de croyances alimentant le processus de la connaissance scientifique à partir duquel se forme le second élément épistémologique: la problématique. [...]

La problématique joue un rôle véritablement stratégique dans l'activité scientifique et pour la comprendre il faut partir de l'idée que la vérité, finalement ce qui est visé par l'entreprise scientifique, est tout entière contenue dans le monde qui nous entoure et en nousmêmes. La vérité, toutefois ne se laisse pas " cueillir » dans son entièreté, et sa complexité la rend inatteignable. En d'autres termes, d'une idée absolue et globale de vérité, nous devons passer à une idée relative et partielle de vérité. Cela équivaut à "questionner » la réalité sur des points circonscrits et selon des modalités bien spécifiques, c'est-à-dire à instituer une problématique qui apparaît, dès lors, comme un «instrument qui sert à rendre intelligible»... quelque chose dans la réalité. Cette opération [...] n'est pas neutre en ce sens qu'elle est déjà un choix fondé métaphysiquement sur un jugement auquel est conféré une pertinence cognitive et/ou sur des inclinations personnelles... donc subjectives. Mais la subjectivité [...] n'interdit pas la cohérence ultérieure de la démarche. Qu'il le veuille ou non, le chercheur institue ou accepte toujours une problématique que ce soit sur le mode implicite ou sur le mode explicite. Dire cela, c'est admettre l'hypothèse que tout exposé scientifique ou non est orienté par quelque chose dont il ne peut pas se débarrasser et qu'on peut trouver dans la structure même du langage préformé qu'il emploie ou auquel il se réfère. Nous ne voulons pas dire qu'une problématique est un sous-produit du langage mais que celui-ci en fournit une si le chercheur a omis d'en expliciter une. [...]

Nous sommes, par là même, amenés au troisième élément épistémologique: la théorie. En première approximation, nous pouvons dire que, si une problématique est une question à propos d'un phénomène de l'univers empirique, une théorie est une réponse qui rend compte du comment et du pourquoi ce phénomène se manifeste de telle manière et pas de telle autre.

D'une manière plus approfondie, nous pouvons dire, avec K. Popper, qu'une théorie est un ensemble argumenté d'énoncés capables d'expliquer déductivement un donné de l'expérience ou de l'observation. Le contenu logique d'une théorie est constitué par la chaîne des implications produites à partir de propositions. Mais ce qui qualifie scientifiquement une théorie est son contenu informatif, soit l'ensemble des conditions empiriques d'incompatibilité, c'est-à-dire ce qui ne doit pas survenir pour que la théorie demeure valable. Plus simplement, la théorie peut aussi être entendue au sens du programme d'observation.

Estudos Geográficos, Rio Claro, 17(1): 309-322, jan./jun. $2019 \quad$ (ISSN 1678-698X) http://www.periodicos.rc.biblioteca.unesp.br/index.php/estgeo 
Le rapport entre théorie et empirie, le quatrième élément épistémologique, est clair. II est, en somme, le moyen d'instruire la validité d'une théorie dans sa confrontation avec les faits. Une théorie sera considérée comme vraie jusqu'à quand, et seulement jusqu'à quand, une de ses assertions ne sera pas contredite (ou falsifiée) par l'expérience. Une théorie s'élabore à partir d'un processus de conceptualisation et par là même n'est pas comparable directement avec l'empirie. Elle l'est, en revanche, par le truchement d'un médiateur technique pertinent, la méthodologie, dont l'adéquation n'est pas évidente comme le montrent par exemple les travaux de $\mathrm{S}$. Gale $^{13}$ (RAFFESTIN; LÉVY, 1998, p. 33-34).

Todavia, é preciso destacar um aspecto peculiar relativo ao primeiro elemento epistemológico considerado pelo autor, no qual as posições ideológicas são atribuídas como representações metafísicas da realidade humana. É como se o conhecimento científico tivesse sua gênese e desenvolvimento de um modo, essencialmente, ilibado das questões sociais e políticas, e, neste sentido, contrário às "modalidades subjetivas" (para acompanhar as expressões de Raffestin) que orientariam uma "razão científica objetiva".

É evidente, por outro lado, que o referido autor não deixa de ponderar o caráter real, ontológico, das determinações ideológicas na prática epistêmica, que "alimenta o processo científico", afastando-o, por sua vez, de uma perspectiva de completa neutralidade. Entretanto, é preciso considerar que seu amparo teórico em Popper $^{14}$ busca definir, "objetivamente", algum horizonte provável entre os campos

\footnotetext{
13 "A metafísica é, antes de tudo, um termo convencional que designa uma vastíssima região do conhecimento: do conhecimento inato ou "subjetivo", ao mesmo tempo, religioso, das modalidades afetivas e éticas que orientam o comportamento e formam as atitudes [ligadas] às ideologias políticas e às crenças supersticiosas. De qualquer modo, a metafísica tem o papel de reservatório de impressões, de convicções e de crenças alimentando o processo de conhecimento científico a partir do qual se forma o segundo elemento epistemológico: a problemática.

A problemática tem um papel, verdadeiramente, estratégico na atividade científica e, para compreendê-la, é necessário partir da ideia de que a verdade, finalmente, isto que é visado pela tarefa científica, está totalmente contida no mundo que nos rodeia e em nós mesmos. A verdade, no entanto, não se deixa "colher" na sua totalidade, e sua complexidade a torna inatingível. Em outros termos, de uma ideia absoluta e global de verdade, nós devemos passar a uma ideia relativa e parcial de verdade. Esta operação equivale a "questionar" a realidade sobre pontos circunscritos e segundo modalidades bem específicas, ou seja, a instituir uma problemática que aparece, por conseguinte, como um "instrumento que serve a tornar inteligível"... alguma coisa na realidade. Esta operação [...] não é neutra no sentido que ela já é uma escolha fundada metafisicamente sobre um julgamento no qual é conferido uma pertinência cognitiva e/ou sobre inclinações pessoais... portanto, subjetivas. Mas a subjetividade [...] não interdita a coerência ulterior do procedimento. Quer queira quer não, o pesquisador institui ou aceita sempre uma problemática que está ligado ao modo implícito ou ao modo explícito. Dizer isso é admitir a hipótese que toda análise científica ou não está orientada por alguma coisa na qual não é possível se desembaraçar e que podemos encontrar na própria estrutura da linguagem pré-formada que ela emprega ou na qual se refere. Nós não queremos dizer que uma problemática é um subproduto da linguagem, mas que esta fornece uma se o pesquisador omitir de explicitar uma. [...]

Somos conduzidos, simultaneamente, ao terceiro elemento epistemológico: a teoria. Em primeira aproximação, nós podemos dizer que, se uma problemática é uma questão relacionada a um fenômeno do universo empírico, uma teoria é uma resposta que dá conta de "como" e "por que" este fenômeno se manifesta de tal maneira e não de outra. De uma maneira mais aprofundada, podemos dizer, com K. Popper, que uma teoria é um conjunto argumentado de enunciados capazes de explicar dedutivamente um dado da experiência ou da observação. O conteúdo lógico de uma teoria constituída por uma cadeia de implicações produzidas a partir de proposições. Mas o que qualifica cientificamente uma teoria é seu conteúdo informativo, seja o conjunto de condições empíricas de incompatibilidade, ou seja, o que não deve ocorrer para que a teoria se torne válida. Mais simplificadamente, a teoria pode também ser entendida no sentido de programa de observação. A relação entre teoria e empiria, o quarto elemento epistemológico, é claro. É, em suma, o meio de instruir a validade de uma teoria em sua confrontação com os fatos. Uma teoria será considerada como verdadeira até quando, e apenas até quando, uma de suas asserções não seja contradita (ou falsificada) pela experiência. Uma teoria se elabora a partir de um processo de conceitualização e por isso mesmo não é comparável diretamente com a empiria. Ela é, ao contrário, por intermédio de um mediador técnico pertinente, a metodologia, na qual a adequação não é evidente como o mostram, por exemplo, os trabalhos de S. Gale." (Tradução livre).

${ }^{14}$ De acordo com Sposito (2004), "no século XX, Karl Popper (1902-1994), filósofo austríaco fortemente influenciado pela filosofia do Círculo de Viena, escola que se notabilizou por recuperar a discussão do que é científico a partir da linguagem Estudos Geográficos, Rio Claro, 17(1): 309-322, jan./jun. 2019 (ISSN 1678-698X)
} http://www.periodicos.rc.biblioteca.unesp.br/index.php/estgeo 
"científico" e "não-científico" (SILVEIRA, 1996), revelando que sua construção em torno das articulações entre ideologia e ciência pouco exprimem organicidade e movimento histórico.

Assim:

A lógica da pesquisa e dos procedimentos científicos para se elaborar conhecimentos, para a tendência neopositivista, teria que se adequar a um sistema lógico de raciocínio [lógica formal], a uma linguagem específica (a linguagem matemática). Todo o conhecimento produzido, por sua vez, teria que passar "pela prova da falseabilidade" para atingir o estatuto científico. [...]

Para Henri Lefèbvre (1983), a lógica formal "pode ser considerada como um dos sistemas de redução do conteúdo, através do qual o entendimento chega a "formas" sem conteúdo, a formas puras e rigorosas, nas quais o pensamento lida apenas consigo mesmo, isto é, com 'nada' de substancial” (SPOSITO, 2004, pp. 32-33).

A dura crítica de Lefèbvre no diz respeito ao esvaziamento do "conteúdo" para o mantenimento da "forma" dos pressupostos científicos aproxima Raffestin, neste aspecto, daquilo que foi denominado como "ruptura ou corte epistemológico" (BACHELARD, 2006), expressão na qual "haveria entre ideologia e ciência uma descontinuidade drástica, de ordem 'qualitativa, teórica e histórica, que podemos designar, com Bachelard, como termo 'corte epistemológico'” (VAISMAN, 2010, p. 42).

Compete indicar que a noção de "ruptura epistemológica" designa, na verdade, uma perspectiva predominantemente gnosio-epistêmica (TONET, 2013). Constata-se, em termos gerais, que as perspectivas gnosio-epistêmicas engendram núcleos metodológicos e estruturas categoriais, essencialmente, apriorísticas do fenômeno empírico estudado. Implicam, por sua vez, análises que, de modo geral, se sobrepõem à base material, isto é, às relações sociais e suas determinações contraditórias e ontológicas, evocando, por conseguinte, uma posição de ampla externalidade do "pesquisador isolado" em relação à concretude de sua atividade científica.

Não é toa, neste sentido, que o critério de "verdade" trazido por Raffestin no segundo elemento epistêmico ("a problemática") seja sempre relativo e parcial, ou seja, seu fundamento decorre de critérios subjetivos do pesquisador e não das relações históricas, ontológicas, do trabalho científico. Esta "verdade" gnosioepistêmica se vaporiza, portanto, em um infindável exercício da razão, cuja dimensão teleológica é ideal, inalcançável.

Em suma, estes aspectos epistêmicos definem traços gerais, contornos parciais, do pensamento de Raffestin, ainda que seja preciso, nestas reflexões preliminares, pontuar mais uma última especificidade do autor no que diz respeito aos processos de conceitualização na ciência geográfica e de que maneira ele concebe o próprio exercício abstrato da teorização (metódico).

Trata-se, na verdade, de uma atividade cognitiva que sofre uma constante "tensão" entre as distintas dimensões relacionadas à realidade (o objeto ou o fenômeno analisado) e ao pensamento (consciência humana). É inegável, neste sentido, as ponderações que o autor toma das reflexões marxianas de Luis Prieto,

matemática, refinando a "linhagem" cartesiana e aprimorando a doutrina positivista com o que se chama, hoje, de uma maneira bastante vulgarizada, de neopositivismo, parte de uma visão materialista da realidade e discute o empirismo" (p. 32).

Estudos Geográficos, Rio Claro, 17(1): 309-322, jan./jun. 2019 (ISSN 1678-698X) http://www.periodicos.rc.biblioteca.unesp.br/index.php/estgeo 
"puisque d'un côté il y a la volonté de ne pas se distancer de la "réalité" mais que de l'autre il y a la necessité de s'en distancer pour se la réprésenter et éventuellement l'expliquer" ${ }^{15 "}$ (RAFFESTIN, 1978, p. 59).

En effet, Prieto distingue 'face à la réalité première et naturelle constituée par la réalité matérielle, ...., une autre realité, seconde et historique, constitué par ces connaissances elles-mêmes. Evidemment, l'activité cognitive peut aussi s'exercer sur cette réalité seconde et donne naissance à ce qu'on appelle les épistémologies qui en ont fait leur objet.

[...] Ainsi, la géographie physique a pour objet la terre considerée d'un ou plusieurs points de vue. II en résulte donc une connaissance. Une science de l'homme n'a pas pour objet une chose qui serait considérée de différents points de vue puisque c'est le point de vue lui-même qui fait la chose: il s'agit donc de la connaissance d'une connaissance mais aussi d'une praxis dans la mesure où connaissance et praxis sont inséparables. C'est pourquoi qui PRIETO, à propos de l'oeuvre de MARX, a pu écrire: "le Capital, par exemple, n'étudie pas le mode de production capitaliste d'un point de vue déterminé, mais, ce qu'il s'efforce de faire, c'est d'expliciter le point de vue déterminé d'où résulte la pertinence de la façon de connaître la réalité matérielle qu'est le mode de production considéré". On pourrait donc dire que la géographie humaine a pour objet la façon dont le sujet agissant connaît et pratique l'environnement dans lequel il est. La géographie humaine a pour tâche d'expliciter les points de vue de cette connaissance et de cette praxis $^{16}$ (RAFFESTIN, 1978, p. 55).

Há, neste ponto, outro apontamento crítico a respeito dos processos de produção do conhecimento pelos geógrafos no sentido de representar a realidade e, "eventualmente", explicá-la; como se "representação" e "explicação" fossem dimensões absolutamente separadas. Ora, os pressupostos teóricos que sustentam as concepções e explicações em "geografia física" não seriam, igualmente, representações de um objeto determinado?

Dito de outra forma, o que Raffestin (1993) tem tomado por "geografia humana", isto é, a ciência que "consiste em explicitar a consciência do conhecimento e da prática que os homens tem dessa realidade [primeira] que é denominada “espaço'” (p. 06), teria uma função tão-somente "representativa" dos fenômenos socioespaciais ("já que é o próprio ponto de vista que faz a coisa")?

\footnotetext{
15 “já que de um lado há a vontade de não se distanciar da 'realidade' mas que de outro há a necessidade de se distanciar para representá-la e, eventualmente, explicá-la” (Tradução livre).

16 "De fato, Prieto distingue 'face à realidade primeira e natural constituída pela realidade material,..., uma outra realidade, secundária e histórica, constituída por estes próprios conhecimentos. Evidentemente, a atividade cognitiva pode também se exercer sobre esta realidade secundária e gerar aquilo que chamamos as epistemologias que fizeram disso seu objeto. [...] Assim, a geografia física tem por objeto a Terra considerada de um ou vários pontos de vista, já que é o próprio ponto de vista que faz a coisa: trata-se, portanto, do conhecimento de um conhecimento, mas também de uma praxis na medida que conhecimento e praxis são inseparáveis. É por isso que PRIETO, em relação à obra de MARX, pôde escrever: "o Capital, por exemplo, não estuda o modo de produção capitalista de um ponto de vista determinado, mas, o que ele se esforça a fazer, é explicitar o ponto de vista determinado do qual resulta a pertinência da maneira de conhecer a realidade material que é o modo de produção considerado". Poderíamos dizer, portanto, que a geografia humana tem por objeto a maneira na qual o sujeito agindo conhece e pratica o meio no qual ele está. A geografia humana tem por tarefa explicitar os pontos de vista deste conhecimento e desta praxis. (Tradução livre).
}

Estudos Geográficos, Rio Claro, 17(1): 309-322, jan./jun. 2019 (ISSN 1678-698X) http://www.periodicos.rc.biblioteca.unesp.br/index.php/estgeo 
Se não se trata de uma ciência que estuda o espaço "em-si" (como a "geografia física", segundo o autor), mas os "pontos de vista", os embates discursivos relativos aos processos relacionais e metabólicos do homem para com a natureza (trabalho), teria, a "geografia humana", uma qualidade talvez "mais subjetiva" ou versamos, no limite, sobre uma falsa questão?

Assim:

En d'autres termes, la géographie humaine est la connaissance de la pratique et de la connaissance que les hommes ont de la réalité matérielle que est l'espace. Dans cette perspective l'objet de la géographie n'est pas l'espace mais les relations que les hommes nouent avec l'espace. L'objet de la géographie n'est donc pas un "donné" mais un "produit".

Par conséquent, si l'objet du géographe est un "système de relations à l'espace", ce système doit être construit. En effet, si les relations sont déchiffrables, elles ne sont pas, au sens strict du terme, visibles. En revanche, elles sont visualisables mais pour les rendre telles, il faut élaborer un appareil conceptuel. On touche, ici, un point importante pour l'épistemologie de la géographie: la "chose" géographique immédiatement visible, un paysage, par exemple, peut être décrit au moyen d'une langue naturelle ou d'un code artistique. C'est la description du romancier qui peut être parfaitement pertinente, admirable, voire géniale, mais qui n'est pas scientifique dans la mesure où elle est le produit d'une conscience et d'une expérience individuelles. La description scientifique nécessite la constrution d'un appareil conceptuel qui permet de passer de la "chose" donné à l'objet géographique à l'aide de concepts aussi univoques que possibles. À cet égard, on peut prendre l'exemple de la cartographie qui est tout à fait illustrant: le passage de l'espace réel à la carte se réalise par la mobilisation d'um appareil conceptuel graphique qui n'est rien d'autre qu'une constrution ${ }^{17}$. [...] (RAFFESTIN; LÉVY, 1998, p. 31).

Seguindo as expressões dos autores, é notável, neste sentido, que o sistema relacional, para ser apreendido sob "critérios científicos" e tornar-se, universalmente, "decifrável" (tal como a linguagem cartográfica), ele deriva de uma "produção" teórico-conceitual. É, na verdade, um produto elaborado a partir de um "aparelho conceitual", capaz de transpassar a condição do objeto geográfico "dado" ("visível"), "comunicando" os processos relacionais.

Em outras palavras, trata-se de uma construção categorial engendrada a partir de uma linguagem específica ou um sistema de códigos ("sêmico"), o qual

\footnotetext{
17 "Em outros termos, a geografia humana é o conhecimento da prática e o conhecimento que os homens tem da realidade material que é o espaço. Nesta perspectiva, o objeto da geografia não é o espaço, mas as relações que os homens estabelecem com o espaço. A geografia não é, portanto, um "dado" mas um "produto".

Consequentemente, se o objeto do geógrafo é um "sistema de relações com o espaço" este sistema deve ser construído. Assim, se as relações são decifráveis, elas não são, no sentido estrito do termo, visíveis. Por outro lado, elas são visualizáveis, mas para torná-las assim, é preciso elaborar um aparelho conceitual. Tocamos, aqui, um ponto importante da epistemologia da geografia: a "coisa" geográfica imediatamente visível, uma paisagem, por exemplo, pode ser descrita mediante uma língua natural ou um código artístico. É a descrição do romancista que pode ser perfeitamente pertinente, admirável, inclusive genial, mas que não é científica na medida que ela é um produto de uma consciência e de uma experiência individuais. A descrição científica precisa da construção de um aparelho conceitual que permite passar da "coisa" dada ao objeto geográfico com a ajuda de conceitos os mais unívocos possíveis. Neste aspecto, podemos tomar o exemplo da cartografia que é absolutamente ilustrante: a passagem do espaço real à carta se realiza pela mobilização de um aparelho conceitual geográfico que não é nada além do que uma construção" (Tradução livre).

Estudos Geográficos, Rio Claro, 17(1): 309-322, jan./jun. $2019 \quad$ (ISSN 1678-698X)
} http://www.periodicos.rc.biblioteca.unesp.br/index.php/estgeo 
expressaria, cientificamente, o sistema relacional, sobrepujando as experiências individuais, subjetivas, dos homens na relação com o espaço ("realidade primeira").

Isto posto, as críticas de Raffestin (1993) a respeito da "perversidade classificatória", que tenta delimitar as categorias "inerentemente" geográficas, tornam-se mais concretas, já que suas resoluções centraram-se, sobremaneira, no "objeto" e não nas relações de poder entre os homens. Segundo o autor, "o poder não é fácil de ser representado, mas é, contudo, decifrável" (p. 06), o que confere, ao poder, a chave "comunicável" e "traduzível" das relações humanas no espaço, conformadoras dos territórios e das territorialidades.

É, sem dúvida, uma consideração bastante perspicaz do autor, antevendo, diante de si, seus embates epistemológicos e ideológicos da época. De um lado, por muito tempo, na tradição de língua francesa, a "paisagem visível" ou o "espaço" vidalino ascendeu à condição de se tornar "objeto" legítimo da "geografia humana", enquanto, no âmbito da geografia política clássica, o conceito de Estado foi, irrefutavelmente, o "objeto privilegiado de toda reflexão política" (RAFFESTIN, 1993, p. 05).

Compete demarcar, nesta direção, que a perspectiva relacional do poder manifestou, ao longo das décadas de 1970 e 1980, uma contraposição obstinada ao que geógrafo suíço denominou de "perspectivas morfofuncionais". Estas abordagens "só representa[vam] a face funcional e não a face 'processual' da relação" (RAFFESTIN, 1993, p. 33), ou seja, perspectivas que externalizavam os sujeitos e os agentes sociais dos processos fundantes (ontológicos) dos territórios.

Em contrapartida, é necessário presumir que uma construção representativa da linguagem (ou um "aparelho conceitual sêmico") sobre as relações humanas no espaço eleva, no cerne da questão, um imbróglio em termos de método.

Cumpre averiguar o que distinguiria o processo de conceitualização do sistema relacional do poder de Raffestin como projeto de "geografia humana" - que, para o autor, delimitaria os campos entre "ciência" e "não-ciência" -, de uma construção apriorística do "objeto geográfico" (predominantemente gnosioepistêmica), relativa tanto à descrição do "dado imediato" da realidade quanto à construção representativa das relações de poder no espaço?

A demarcação das representações sêmicas na centralidade de seu projeto teórico reforçaria uma perspectiva logicizante de sua "geografia do poder", ainda que se reivindique medularmente as relações sociais de poder na base de suas reflexões e interpretações geográficas?

Esta questão, evidentemente, não poderia se esgotar nas discussões de um artigo, embora, o que tenhamos feito no presente texto, foi uma tentativa de reavivar pilares epistemológicos e ideológicos centrais do geógrafo suíço. À luz des tensionamento de método, especificamente de uma abordagem ontológica e materialista, cotejamos a problemática relacional do poder em suas refrações conceituais e resolutivas no que tange às mediações entre subjetividade e objetividade.

Em todo caso, manifestamos o caráter ainda incipiente das reflexões, muito embora focalizam questões essencialmente desconhecidas de Claude Raffestin no Brasil, principalmente em relação à uma análise mais aprofundada de seu pensamento geográfico.

Estudos Geográficos, Rio Claro, 17(1): 309-322, jan./jun. $2019 \quad$ (ISSN 1678-698X) http://www.periodicos.rc.biblioteca.unesp.br/index.php/estgeo 


\section{CONSIDERAÇÕES FINAIS}

Estas reflexões, que tomam um escopo mais provocativo do que propriamente resolutivo acerca das questões epistêmicas, metodológicas e ideológicas do projeto geográfico de Claude Raffestin, não se esgotam, por razões óbvias, neste texto.

Todavia, acredita-se que, apesar do caráter intencionalmente aberto dos problemas apresentados, alguns pontos podem ser encaminhados. Isto significa dizer que: i. se foi possível abarcar aspectos inexplorados da "geografia do poder", ampliando as compreensões e apreensões de Claude Raffestin no debate geográfico brasileiro; ii. se foi possível questionar a materialidade e densidade histórica da problemática relacional do poder sem minimizar a riqueza das concepções geográficas do autor; iii. Se foi possível identificar criticamente a sutileza da abordagem relacional frente aos embates com a geografia política clássica e a tradição vidalina; encerramos este breve texto momentaneamente satisfeitos.

\section{REFERÊNCIAS}

BACHELARD, Gaston. A epistemologia. Trad.: Fátima L. Godinho; Mário C. Oliveira. Lisboa: Portugal: Edições 70, 2006.

CHEPTULIN, Alexandre. A Dialética Materialista. Categorias e leis da dialética. Trad.: Leda Rita Cintra Ferraz. São Paulo: Editora Alfa-Omega, 1982. 354 p.

CLAVAL, Paul. Espaço e poder. Trad. Waltensir Dutra. Rio de Janeiro: Zahar Editores, 1979.

GREIMAS, Algirdas Julius. Sémiotique et sciences sociales. Paris: Seuil, 1976.

HARTSHORNE, Richard. The Nature of Geography. Michigan: Edwards Brothers, 1949.

KOSIK, Karel. Dialética do concreto. Trad.: Célia Neves e Alderico Toríbio. $2^{\underline{a}}$ ed. Rio de Janeiro: Paz e Terra, 1976.

LEFEBVRE, Henri. La Production de I'Espace. 4ํㅗㄹ ed. Paris: Éditions Anthropos, 2000.

LÖWY, Michael. As Aventuras de Karl Marx contra o Barão de Münchhausen. Marxismo e positivismo na sociologia do conhecimento. Trad.: Juarez Guimarães e Suzanne Felicie Léwy. 7ª ed. São Paulo: Cortez, 2000. 219 p.

RAFFESTIN, Claude. Space, territory and territoriality. Environment and Planning D : Society and Space, 2012, vol. 30, pp. 121-141.

RAFFESTIN, Claude; LÉVY, Bertrand. Epistémologie de la géographie humaine. In: BAILLY, A. Les concepts de la géographie humaine. Paris: Armand Colin, 1998, p. 25-36.

Estudos Geográficos, Rio Claro, 17(1): 309-322, jan./jun. $2019 \quad$ (ISSN 1678-698X) http://www.periodicos.rc.biblioteca.unesp.br/index.php/estgeo 
RAFFESTIN, Claude. Por Uma Geografia do Poder. Trad.: Maria Cecília França. Editora Ática, 1993.

RAFFESTIN, Claude. Territorialité: concept ou paradigme em géographie sociale? Geographica Helvetica 2, 1986, pp. 91-96.

RAFFESTIN, Claude. Travail et territorialité. In: Demain le travail. Paris : Economica, 1982, pp. 147-154.

RAFFESTIN, Claude ; BRESSO, Mercedes. Travail, espace et pouvoir. Ed. L'Age d'Homme, Lausanne, 1979.

RAFFESTIN, Claude. Les construits em géographie humaine: notions et concepts. In: Géopoint 78: Concepts et construits dans la géographie contemporaine, 1978, p. 55-73.

RAFFESTIN, Claude. Peut-on parler des codes dans les sciences humaines et particulièrement en géographie? L’Espace Géographique, Paris, № 3, 1976, p. 183188.

RAFFESTIN, Claude. Géographie humaine et méthodes d'analyse. Le Globe, n. 111,1974 , p. 53-64.

RAFEFSTIN, Claude. Problématique implicite et problématique explicite en géographie humaine. Geographica Helvetica, 1974, n. 2/3, pp. 22-28.

SILVEIRA, Fernando Lang. A filosofia da ciência de Karl Popper: o racionalismo crítico. Cad. Cat. Ens. Fis., v. 13, n. 3, pp. 197-218, 1996.

SÖDERSTRÖM, O.; PHILO, C. Social geography: looking for geography in its spaces. In: BENKO, G; STROHMAYER, U., Human Geography: A History for the Tweenty-first Century. Blackwell, Oxford, 2004, pp. 105-138.

SOUZA, José Gilberto de. A Questão Indígena: Acumulação por Espoliação e Monopolização do Território (A economia política do agronegócio). Revista Prima Facie, v. 12, n. 22, 2013, pp. 01-42.

SOUZA, José Gilberto de. Limites do Território. Revista Agrária, São Paulo, no 10/11, 2009, pp. 99-130.

SPOSITO, Eliseu S. Geografia e Filosofia. Contribuição para o ensino do pensamento geográfico. São Paulo: Editora Unesp, 2004.

TONET, Ivo. Método Científico: uma abordagem ontológica. São Paulo: Instituto Lukács, 2013.

VAISMAN, Ester. A Ideologia e sua Determinação Ontológica. Revista Verinotio, no 12, ano VI, out./2010, pp. 40-64. 